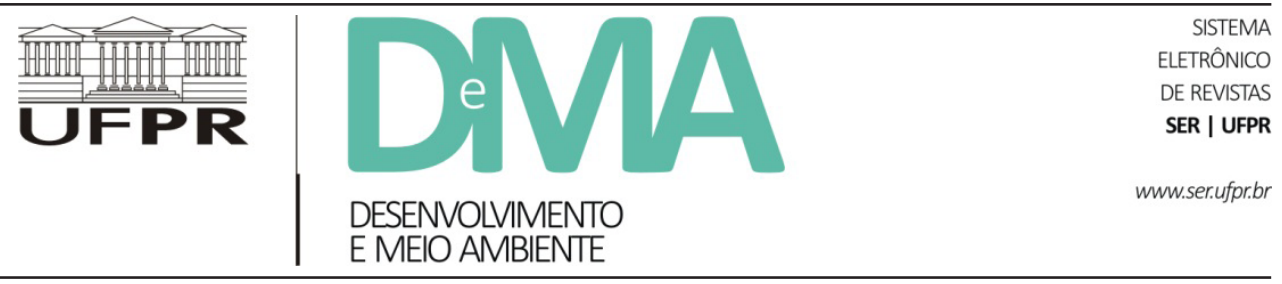

\title{
Avaliação da efetividade da integração das Unidades de Conservação federais marinho-costeiras de Santa Catarina
}

\section{Evaluation of the Integration Effectiveness Among the Coastal Marine Federal Protected Areas of Santa Catarina}

\author{
Apoena Calixto FIGUEIROA ${ }^{1 *}$, Glauce BRASIL ${ }^{1}$, Andrea PELLIN ${ }^{1}$, Marinez Eymael Garcia SCHERER ${ }^{1}$ \\ ${ }^{1}$ Programa de Pós-Graduação em Geografia (PPGGEO), Universidade Federal de Santa Catarina (UFSC), Florianópolis, SC, Brasil. \\ *E-mail de contato: apoenafigueiroa@gmail.com
}

Artigo recebido em 5 de junho de 2016, versão final aceita em 11 de agosto de 2016.

RESUMO: Os ambientes marinho-costeiros do Brasil são os mais afetados pelo processo de ocupação humana, ocasionando considerável degradação ambiental, sendo necessárias ações que orientem um gerenciamento integrado, visando manter a integridade dos ecossistemas. No Brasil, uma das estratégias utilizadas para conservação do meio ambiente e gestão da zona costeira é a criação de unidades de conservação (UC). A lei que cria o Sistema Nacional de Unidades de Conservação define diretrizes para que unidades de conservação próximas, justapostas ou sobrepostas sejam geridas de forma integrada e participativa. Nesse sentido, as UCs marinho-costeiras de Santa Catarina foram objeto de iniciativas visando à integração da gestão das UCs federais no Estado que culminaram na criação do Núcleo de Gestão Integrada das Unidades de Conservação Marinho-Costeiras de Santa Catarina. O presente trabalho visa avaliar o quanto essas iniciativas realmente se traduziram em ações práticas hoje estabelecidas, bem como os motivos do alcance ou não desses resultados. Embora tenham sido observados trabalhos envolvendo o apoio entre as UCs, estes não puderam ser caracterizados como parte de uma gestão integrada, já que a mesma deveria partir da premissa de que o planejamento e as decisões sejam construídos de forma conjunta, visando ao território como um todo. Necessária se faz a real integração das UCs federais em análise. Essa integração não deverá se limitar a suprimir as deficiências estruturais do órgão público, mas garantir o atendimento às exigências legais, às normativas institucionais e às decisões coletivas, alcançando uma maior coerência da gestão territorial, assim como uma maior eficiência na conservação dos ecossistemas e na manutenção e no ordenamento dos serviços a eles associados.

Palavras-chave: mosaico; gestão integrada; unidades de conservação, zona costeira e marinha.

ABSTRACT: Coastal-marine environments in Brazil are the most affected by the human occupation process, causing considerable environmental degradation, requiring actions to guide an integrated management in order to maintain the integrity of ecosystems. In Brazil, one of the strategies used for environmental conservation and coastal area management is the creation of Conservation Units. The law under which the Sistema Nacional de Unidades de Conservação (National System of Conservation Units) (SNUC) was created, sets forth guidelines 
for the management of nearby, juxtaposed or superimposed conservation units in an integrated and participatory manner. In this sense, the coastal-marine Santa Catarina CUs were subject to initiatives aimed at integrating the management of federal CUs in the state, which culminated in the creation of the Center for Integrated Management of Coastal-Marine Conservation Units in Santa Catarina. This study aims to assess to what extent these initiatives were actually translated into the practical actions currently established, as well as the reasons for achieving these results, or not. Although we observed work involving support among CUs, such work could not be characterized as part of an integrated management, as such management should start from the premise that planning and decisions are to be built together, viewing the territory as a whole. It is necessary to actually integrate those federal conservation units under analysis. This integration should not be limited to eliminating the structural deficiencies of the public agency, but ensuring compliance with legal requirements, institutional regulations and collective decisions, achieving greater coherence in territorial management, as well as greater efficiency in the conservation of ecosystems and maintenance and management of the services associated with them.

Keywords: mosaic; integrated management; conservation units, coastal and marine area.

\section{Introdução}

Na região costeira do Brasil circula mais da metade do PIB do país, vivem perto de 45 milhões de pessoas ( $24 \%$ da população) e encontram-se 16 das 28 maiores metrópoles brasileiras (MMA, 2015). Assim, os ambientes marinho-costeiros do Brasil estão entre os mais afetados pelo processo de ocupação humana, ocasionando considerável degradação ambiental, sendo necessárias ações que orientem a gestão integrada, visando manter a integridade dos ecossistemas (Asmus et al., 2004). Tais alterações ambientais vêm ocasionando a perda de serviços ecossistêmicos e seus benefícios, afetando as populações que dependem direta ou indiretamente destes serviços (Scherer \& Asmus, 2016).

Assim como em grande parte dos países do globo, no Brasil uma das estratégias utilizadas para conservação do meio ambiente e gestão da zona costeira é a criação de áreas protegidas, em especial de unidades de conservação (UC). Tal estratégia se sedimenta na legislação federal (Brasil, 1988) quando essa define que o Plano Nacional de Gerenciamento Costeiro - PNGC - e demais instrumentos dele derivados deverão prever o zo- neamento de usos e atividades na Zona Costeira, dando prioridade à conservação e à proteção, entre outros bens, das UCs.

A regulamentação da legislação que envolve o PNGC (Brasil, 2004) reforça que as UCs são consideradas trechos de interesse especial da orla marítima. Finalmente, o PNGC atual (Brasil, 1997) coloca como uma de suas principais diretrizes compatibilizar as ações do plano com as políticas públicas que incidam sobre a Zona Costeira, incluindo expressamente as UCs, de modo a estabelecer parcerias, visando à integração de ações e à otimização de resultados. Apesar da importância que deveria se dar a essas áreas na gestão integrada da zona costeira, conforme informações do Ministério do Meio Ambiente - MMA, apenas 3,14\% da área costeira e marinha está protegida por UCs (MMA, 2015).

Essas UCs, por sua vez, seguem os princípios definidos pelo Sistema Nacional de Unidades de Conservação, SNUC, que, dentre outras questões, define diretrizes para que as UCs de categorias diferentes ou não, que se localizem próximas, justapostas ou sobrepostas, sejam geridas de forma integrada e participativa (Brasil, 2000a). Tal integração 
na gestão das UCs marinho-costeiras é ressaltada no Plano Nacional de Áreas Protegidas - PNAP, que determina em seus princípios, diretrizes e eixos temáticos a adoção da abordagem ecossistêmica na gestão das áreas protegidas (Brasil, 2006). Ainda conforme o PNAP, esse sistema de áreas protegidas, no caso das áreas costeiras e marinhas, deve ser formado por uma rede de áreas altamente protegidas, integrada a uma rede de áreas de uso múltiplo.

Conceitualmente, pode-se dizer que gestão integrada de unidades de conservação é aquela que é realizada de maneira compartilhada, em que as metas e os objetivos levem a uma visão de futuro comum, vinculada às possibilidades de compartilhamento de tarefas e responsabilidades (Sales, 2012).

Com vistas ao atendimento de todas essas premissas, o MMA lançou em 2015 o projeto "Proteção e Gestão Integrada da Biodiversidade Marinha e Costeira" - Projeto TerraMar (MMA, 2015), que, focado nas UCs, tem por objetivo garantir que o planejamento ambiental territorial e a gestão integrada da zona marinha e costeira contribuam para a proteção e para o uso sustentável de sua biodiversidade.

Analisando-se essas premissas, uma das perguntas que restam ser respondidas é: essa integração, que deveria ser a base de toda gestão da zona costeira, ocorre ao menos entre as UCs marinho-costeiras de âmbito federal, já que essas são geridas pelo mesmo órgão gestor?

No litoral de Santa Catarina existem cinco UCs federais: a Reserva Biológica Marinha do Arvoredo (REBIO Arvoredo), criada em 12 de março de 1990, com área total de 17.104,47 ha (Brasil,1990); a Estação Ecológica de Carijós (ESEC Carijós), criada em 20 de julho de 1987, com área total de 759,3 ha (Brasil, 1987); a Área de Proteção Ambiental de Anhatomirim (APA Anhatomirim), criada em 20 de maio de 1992, com área total de 4.436,56 ha (Brasil, 1992a); a Reserva Extrativista do Pirajubaé (RESEX Pirajubaé), criada em 20 de maio de 1992, com área total de 1.712,08 ha (BRASIL, 1992b); e a Área de Proteção Ambiental da Baleia Franca (APA Baleia Franca), criada em 14 de setembro de 2000, com área total de 154.866,27 ha (Brasil, 2000b).

Essas UCs, além de estarem próximas entre si, encontram-se subordinadas à mesma coordenação regional do Instituto Chico Mendes de Conservação da Biodiversidade - ICMBio; assim, para efeitos deste trabalho, considera-se que essas UCs integram um mesmo território. Três delas (REBIO Arvoredo, APA Anhatomirim e ESEC Carijós) encontram-se sediadas no mesmo local, na ESEC Carijós. Ainda, quatro delas (REBIO Arvoredo, APAAnhatomirim, ESEC Carijós e RESEX Pirajubaé) se encontram sediadas no município de Florianópolis/SC e a APA Baleia Franca é sediada no município de Imbituba/ $\mathrm{SC}$, a menos de cem quilômetros de Florianópolis. Isso leva a crer que a questão geográfica e a questão institucional não deveriam representar dificuldades para a gestão integrada dessas UCs, ao contrário, deveriam contribuir para tal integração.

Conforme Souza (1995), território é o espaço definido e delimitado por e a partir de relações de poder. Para o presente trabalho, define-se como o território a ser abordado a abrangência de ação do poder público representado pelo ICMBio no litoral catarinense. Esse espaço corresponde às UCs federais e seu entorno, compreendido até onde as atividades humanas possuam relação direta de causa e efeito com essas UCs (ICMBio, 2012).

Além disso, associadas às áreas definidas das $\mathrm{UCs}$, as propostas técnicas das zonas de amortecimento da REBIO Arvoredo, da ESEC Carijós e da RESEX Pirajubaé (as APAs não possuem legalmente esse instrumento) para a área marinha, 
em alguns locais, se justapõem e/ou sobrepõem, intensificando o entendimento pela interconectividade entre essas áreas.

Na Figura 1 observam-se a localização das UCs federais marinho-costeiras de Santa Catarina ao longo do litoral do Estado, assim como, em detalhe, as UCs localizadas na Ilha de Santa Catarina e em suas proximidades.

No mapa da Figura 2, com o acréscimo das zonas de amortecimento hoje tecnicamente propostas para as UCs em análise, fica ainda mais evidente a conexão, principalmente marinha, entre essas áreas.

Porém, Debetir (2006) indica em seu trabalho uma baixa eficácia e qualidade na gestão dessas UCs, salientando que as razões para isso são a má aplicação dos recursos humanos, materiais, financeiros e técnicos existentes, além da cultura organizacional vigente que privilegia, dentre outras coisas, a concorrência em detrimento da parceria e a fragmentação em detrimento da integração. Ressalta ainda que, para haver gestão integrada, esta deve incluir o estabelecimento de uma prática institucional de integração intra e interinstitucional capaz de elaborar agendas comuns. A autora também recomenda analisar a Ilha de Santa Catarina de forma holística, numa cadeia de inter-relações, onde juntar a gestão das unidades de conservação é o primeiro passo, sendo que o segundo deveria ser integrar a gestão das UCs com a gestão urbana, pois ambas compõem a gestão territorial.
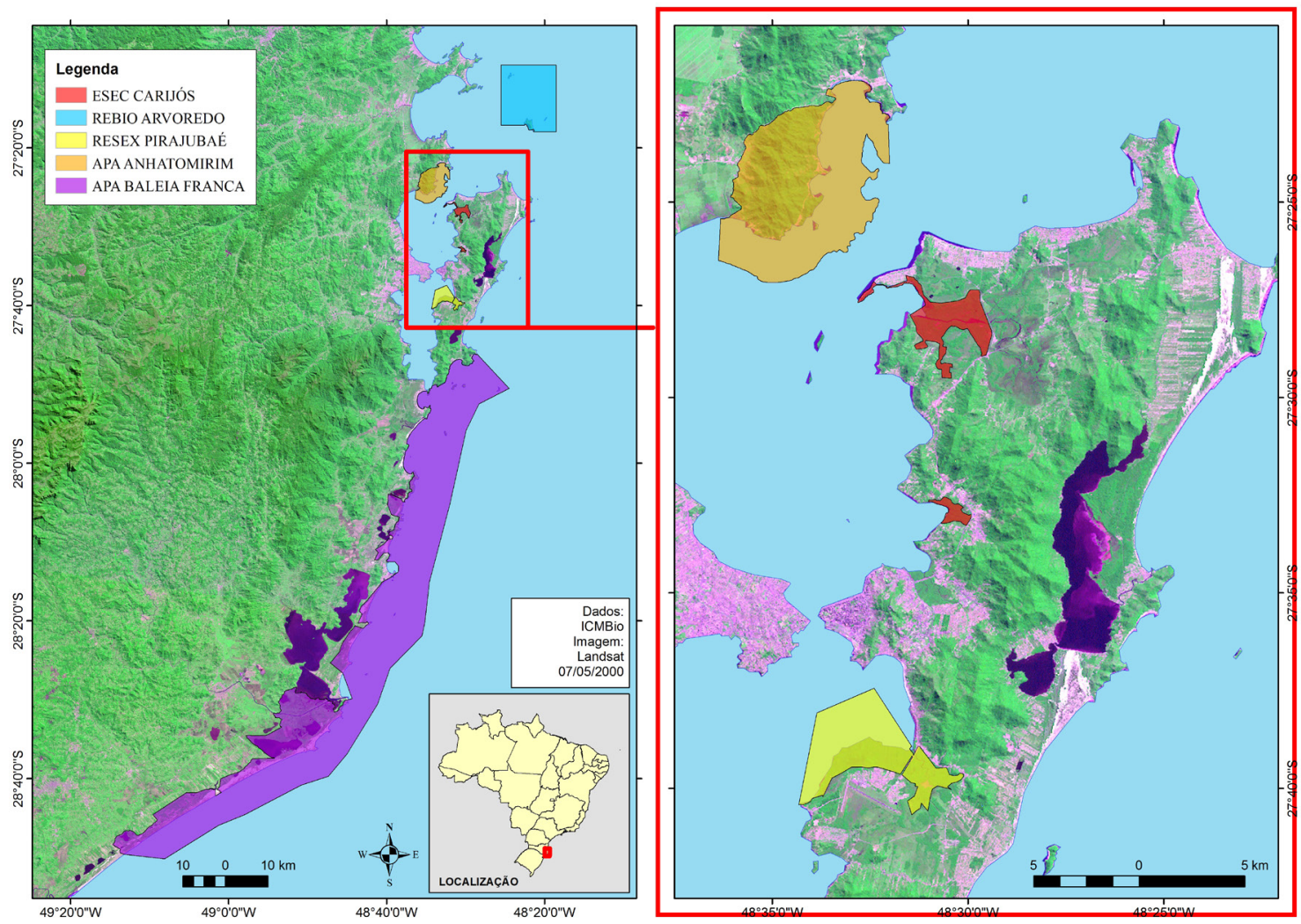

FIGURA 1 - Mapa das UCs federais marinho-costeiras de Santa Catarina.

FONTE: Elaboração própria; dados vetoriais: ICMBio (2016b). 


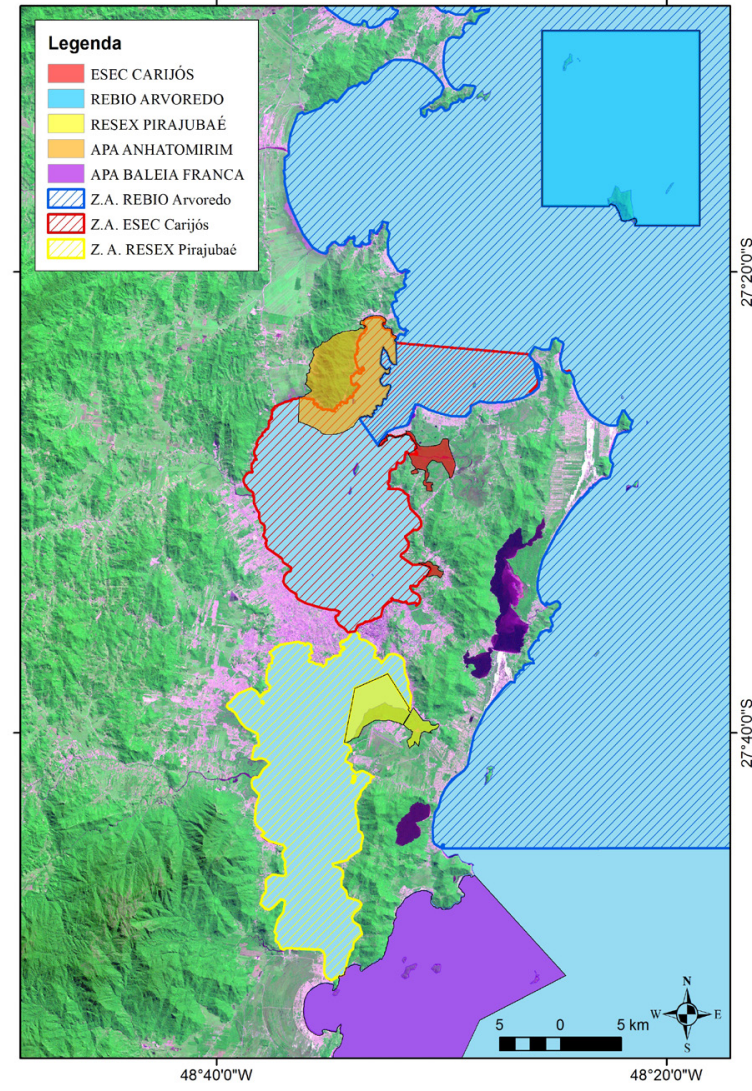

FIGURA 2 - Mapa das UCs federais marinho-costeiras de Santa Catarina e suas propostas técnicas de zona de amortecimento. FONTE: Elaboração própria; dados vetoriais: ICMBio (2016b).

Nesse contexto, uma importante iniciativa institucional de integração na gestão das UCs federais marinho-costeiras de Santa Catarina, por meio do Núcleo de Gestão Integrada de Unidades Marinho-Costeiras de Santa Catarina - NGI-UMC/ SC, foi instituída em 2011 (ICMBio, 2011a), objetivando contribuir para a gestão integrada da região por meio da união de esforços, da otimização de recursos e da resolução de questões comuns às unidades descentralizadas do ICMBio. Essa iniciativa englobou a REBIO Arvoredo, a APAAnhatomirim, a ESEC Carijós, a RESEX Pirajubaé, a APA Baleia
Franca, o Centro de Pesquisa e Conservação de Tartarugas Marinhas - TAMAR/SC, o Centro de Pesquisa e Conservação de Aves - CEMAVE/SC - e o Centro de Conservação de Mamíferos Aquáticos - CMA/SC. Esse modelo de gestão continua vigente até hoje e conta com um Regimento Interno que define, entre outras questões, uma estrutura de gestão, composta por colegiados de gestores e servidores, a periodicidade de reuniões desses colegiados, assim como a forma de execução das atividades integradas e a gestão de recursos.

Segundo Cifuentes et al. (2000), a efetividade das áreas protegidas é considerada como o conjunto de ações baseadas nas atitudes, habilidades e competências particulares que permitem alcançar os objetivos e as funções para os quais as áreas foram criadas. Dessa forma, é perfeitamente possível aplicar o mesmo conceito a um coletivo de unidades e seu entorno, como o caso que aqui se analisa, visando ao território como um todo.

Sendo assim, o objetivo principal do presente trabalho é uma avaliação da efetividade da integração da gestão das UCs marinho-costeiras de Santa Catarina e, como forma de se atingir esse objetivo, identificar iniciativas anteriores ao NGI-UMC/ $\mathrm{SC}$ e a visão dos servidores sobre a integração da gestão das UCs, assim como identificar possíveis potenciais e dificuldades dessa integração.

\section{Material e métodos}

\subsection{Procedimentos metodológicos}

Como procedimentos metodológicos para a obtenção de dados importantes ao presente trabalho, foram adotados:

- Análise do histórico e dos instrumentos de integração das UCs federais marinho- 
-costeiras de SC por meio de documentos oficiais e pesquisa na rede mundial de computadores, utilizando as seguintes palavras-chave: gestão integrada; unidades de conservação de Santa Catarina; mosaico de unidades de conservação;

- Análise da execução de recursos financeiros destinados à integração;

- Análise dos planos de manejo das UCs em questão, no que diz respeito à integração da gestão;

- Análise, por meio de entrevistas, da percepção de servidores e gestores do ICMBio acerca da integração das UCs federais marinho-costeiras de SC; e

- Análise da efetividade atual do NGI-UMC/ SC com base na interpretação da portaria de criação do NGI, seu regimento interno, atas de reuniões e informações obtidas nas entrevistas.

Objetivando captar o entendimento dos atores que trabalham na gestão das UCs analisadas sobre os conceitos e a realidade da integração na gestão dessas unidades, foram entrevistados cinco servidores das UCs, os cinco chefes dessas unidades e o coordenador regional em Florianópolis. Tanto os chefes quanto o coordenador regional foram considerados gestores locais das UCs para fins do presente trabalho. Os entrevistados concordaram em participar francamente da pesquisa, mediante assinatura de um Termo de Consentimento Livre e Esclarecido.

A técnica utilizada para este trabalho foi a entrevista semiestruturada. Esta técnica foi a escolhida por delimitar o volume de informações, obtendo, assim, um maior direcionamento para o assunto de interesse, ao mesmo tempo em que as questões abertas permitem um maior detalhamento do tema e a investigação de aspectos afetivos e valorativos dos entrevistados (Boni \& Quaresma, 2005). O questionário foi entregue aos entrevistados no início das entrevistas, para que eles respondessem as questões fechadas, enquanto as respostas das questões abertas foram gravadas e transcritas na íntegra, com a posterior seleção das partes relevantes à pesquisa.

Por fim, se buscou avaliar o quanto as iniciativas de integração, caso tenham existido, se traduziram em ações práticas hoje estabelecidas, bem como os motivos do alcance ou não desses resultados.

\section{Resultados e discussões}

\subsection{Iniciativas de integração}

Analisando-se documentos relativos às iniciativas de integração das UCs marinho-costeiras de Santa Catarina, constatou-se que algumas delas ocorreram localmente de forma importante. As iniciativas que se destacaram foram, em ordem cronológica, o GIUC (Gestão Integrada das Unidades de Conservação de Santa Catarina), o RUMAR (Rede de Unidades Marinhas) e o NGI-SC, já comentado anteriormente.

O GIUC foi fruto de um Grupo de Trabalho-GT instituído em 2002 (MMA, 2002), o qual objetivou o desenvolvimento do processo de integração entre as UCs na forma de um mosaico, a ser instituído envolvendo as UCs federais REBIO Arvoredo, ESEC Carijós, APA Anhatomirim, RESEX Pirajubaé e APA Baleia Franca, além do Parque Estadual da Serra do Tabuleiro. Embora esta iniciativa tenha gerado diversos documentos e, ao menos à época, uma real aproximação entre as unidades, esse mosaico não foi formalmente instituído. 
O Programa Rede de Unidades Costeiras e Marinhas do IBAMA - RUMAR - foi um programa iniciado em 2004 e formalizado em 2008 (Descrito no Processo IBAMA n ${ }^{\circ}$ 02070.002416/2008-20), que teve como objetivo promover o desenvolvimento de ações integradas de proteção, monitoramento e geração de conhecimentos por intermédio das unidades descentralizadas do IBAMA, visando maior eficiência e efetividade na gestão dos recursos naturais e das UCs federais nas zonas marinha e costeira. Além das UCs, que eram as peças centrais, a proposta também abrangia os centros de pesquisa, os escritórios regionais e as gerências executivas do IBAMA. O programa abrangia todo o litoral brasileiro, que era dividido em 48 bases de importância estratégica para a proteção e para o monitoramento da costa e ilhas oceânicas brasileiras, compostas por 74 unidades descentralizadas. O RUMAR era fortemente focado na integração das unidades e na estruturação física e financeira das bases.

Das 48 bases previstas, duas foram consideradas as bases-piloto do programa, sendo essas a Base Parque Nacional (PARNA) Abrolhos e a Base REBIO Arvoredo. A Base REBIO Arvoredo, objeto deste estudo, era composta das seguintes unidades descentralizadas do IBAMA: REBIO Arvoredo, APA Anhatomirim, ESEC Carijós, RESEX Pirajubaé, APA Baleia Franca, Centro de Pesquisa e Conservação de Tartarugas Marinhas - TAMAR/ SC, Centro de Pesquisa e Conservação de Aves CEMAVE/SC, Centro de Conservação de Mamíferos Aquáticos - CMA/SC, Centro de Pesquisas em Recursos Pesqueiros do Litoral Sul - CEPSUL, Superintendência do IBAMA - SUPES/SC, Escritório Regional - ER de Laguna e Escritório Regional - ER de Itajaí.

Com vistas à implantação das bases-piloto, foram destinados em 2006 recursos oriundos de compensação por significativo impacto ambiental do campo de produção de óleo e gás de Bijupirá \& Salema, localizado na Bacia de Campos, da empresa Shell. Embora essas duas iniciativas anteriores não tenham tido continuidade por parte da instituição, deixaram documentos importantes, não só como diagnósticos, mas também como subsídios para propostas posteriores. Tais iniciativas também influenciaram nos planos de manejo até hoje elaborados para as UCs analisadas. Além disso, de forma importante, elas inevitavelmente acabaram por contribuir para a cultura de integração entre os servidores das UCs.

\subsection{Planos de Manejo das unidades de conservação}

Em se falando em gestão de UCs, é necessário analisar os planos de manejo das UCs que os possuem, que são os documentos aptos a dar as diretrizes de trabalho à gestão dessas áreas, conforme prevê a legislação (Brasil, 2000a).

Das cinco UCs analisadas, três possuem plano de manejo. Sendo assim, foram esses planos submetidos à análise no que tange à integração na gestão dessas unidades.

Os planos de manejo oficialmente publicados, em ordem cronológica, foram o plano de manejo da ESEC Carijós (IBAMA, 2003), o plano de manejo da REBIO Arvoredo (IBAMA, 2004), a monitoria e a revisão pelas quais passou o plano de manejo da ESEC Carijós (ICMBio, 2011b) e o plano de manejo da APA Anhatomirim (ICMBio, 2013).

Todas essas publicações, sem exceção, dão grande ênfase à necessidade de integração na gestão das cinco UCs. Ao analisarem o contexto local, definem a integração como uma oportunidade, incluindo-a, de forma linear dentre os documentos publicados, como uma ação gerencial na gestão das 
unidades. Nesse quesito, é possível dar destaque aos dois documentos mais recentes, a monitoria do plano de manejo da ESEC Carijós, que trata do assunto de forma reiterada em praticamente toda a sua extensão, e o plano de manejo da APAAnhatomirim, que contém um capítulo só sobre o assunto.

Fica claro que os planos de manejo foram influenciados pelos processos de integração da gestão realizados ao longo do tempo, demonstrando uma importante contribuição dessas iniciativas.

\subsection{Percepção dos servidores acerca da gestão integrada}

Os questionários semiestruturados aplicados foram compostos por perguntas abertas e fechadas (com respostas do tipo "sim" e "não"). Com o resultado das perguntas fechadas, foi possível a visualização dos resultados gerais em gráficos com diferenciação quanto à função do entrevistado. Em todos os gráficos, a coluna vertical representa o número de entrevistados que responderam às questões e na horizontal têm-se as respostas obtidas.

Em questão que envolvia a existência de cooperação e compartilhamento de espaço, veículos ou equipamentos entre as UCs observou-se que a grande maioria dos entrevistados entende que essa existe (Figura 3). Este dado representa um grande potencial para gestão integrada, embora, por si só, não signifique a existência de tal integração.

Em complemento à questão anterior, sem discutir com o entrevistado o conceito de gestão integrada, questionou-se sobre a existência na prática de uma gestão integrada entre as UCs em análise. Nesse quesito, mesmo com uma diferença não significante, a maioria dos entrevistados entendeu pela existência de integração na gestão das unidades (Figura 4).

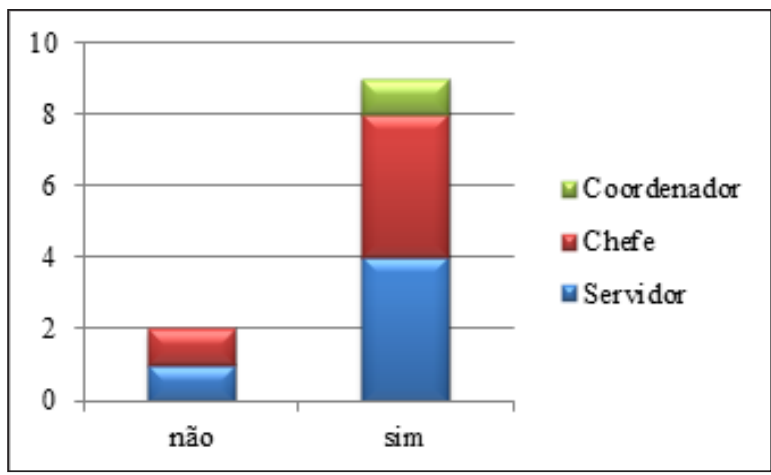

FIGURA 3 - Gráfico sobre a visão dos entrevistados quanto à existência de cooperação e compartilhamento entre as UCs. FONTE: Elaboração própria a partir das entrevistas.

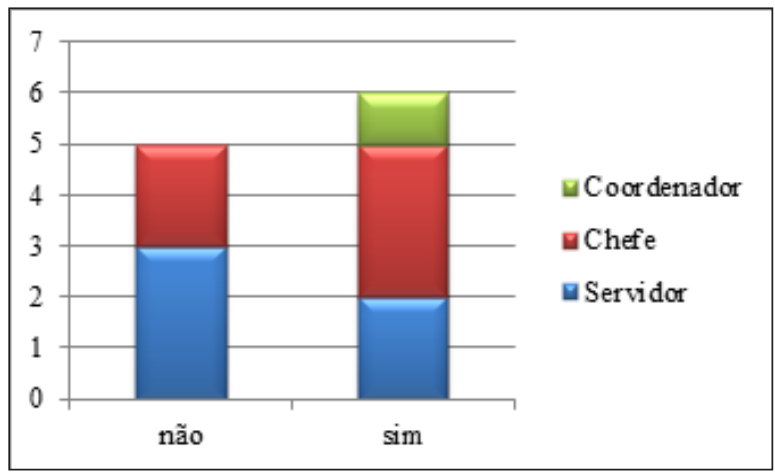

FIGURA 4 - Gráfico sobre a visão dos entrevistados quanto à existência de integração na gestão entre as UCs.

FONTE: Elaboração própria a partir das entrevistas.

É interessante observar que, ao se estratificar o resultado pela função que o entrevistado exerce na gestão, vê-se que os gestores majoritariamente entendem a gestão como integrada, enquanto que a maioria dos servidores não gestores entende que não existe tal integração.

Porém, quando o entrevistado foi questionado sobre o que ele entende como gestão integrada, foi possível observar uma variação dos conceitos envolvidos na resposta. Embora a maioria tenha citado a palavra "território", sem definição conceitual sobre o que se referiam, os entrevistados trouxeram conceitos de gestão integrada que variaram 
desde a realização de ações de interesse comum ou sentimento de integração entre os servidores até a realização de planejamento integrado. Essa disparidade de entendimento no conceito relacionado ao cerne da questão envolvendo a integração pode representar um empecilho para o estabelecimento de uma gestão territorial integrada. Este dado denota a necessidade de maior formação por parte dos técnicos e gestores.

Ao indagar aos entrevistados se o planejamento e as tomadas de decisões que envolvem a gestão das UCs são definidos em conjunto, a grande maioria respondeu que não (Figura 5). Esses dois parâmetros, planejamento e decisão, figuram entre os principais pilares de qualquer conceito de gestão, assim, esse resultado fornece fortes indícios de que em verdade a integração da gestão dessas unidades não existe na prática.

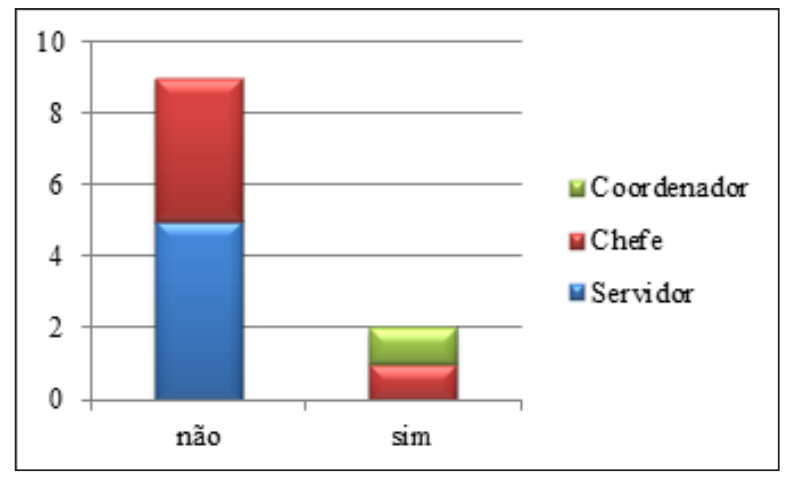

FIGURA 5 - Gráfico sobre a visão dos entrevistados quanto à existência de integração no planejamento e nas tomadas de decisões das UCs.

FONTE: Elaboração própria a partir das entrevistas.

Novamente se vê uma diferença na proporção entre gestores e não gestores nas respostas, sendo que as únicas duas respostas positivas quanto à existência de integração no planejamento e tomada de decisão foram dos coordenadores.

Quando questionados sobre se o uso dos recursos de compensação ambiental e outras fontes orçamentárias são discutidos conjuntamente entre as UCs, a maioria dos entrevistados respondeu que não (Figura 6).

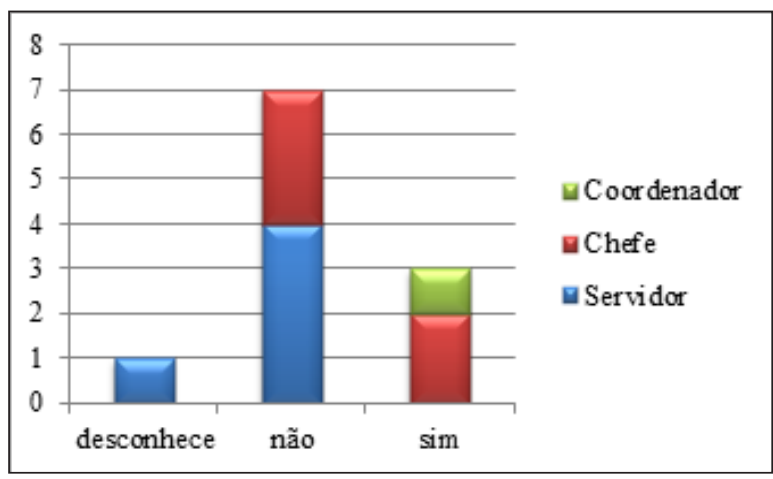

FIGURA 6 - Gráfico sobre a visão dos entrevistados quanto à existência de integração no uso dos recursos de compensação ambiental e outras fontes orçamentárias das UCs.

FONTE: Elaboração própria a partir das entrevistas.

Nota-se, novamente, uma acentuada diferença entre a resposta dos gestores e não gestores, sendo que todas as afirmações positivas à integração nesse quesito foram emanadas por gestores.

Quando novamente questionados sobre a existência de uma gestão integrada entre as unidades, após fornecer o conceito de gestão integrada como contendo planejamento e tomadas de decisão em conjunto com foco em uma gestão territorial ampla, o entendimento dos entrevistados se inverte. Dessa vez a maioria declara que inexiste tal integração (Figura 7).

Isso mostra como é importante um balizamento entre os atores envolvidos na gestão sobre conceitos básicos de gestão integrada. Explicando-se três pilares essenciais - planejamento conjunto, tomada de decisão conjunta e gestão territorial ampla, a visão sobre a realidade da integração se inverte em relação à mesma pergunta realizada sem balizamento anterior sobre o conceito (Figura 4).

Como nos questionamentos anteriores, também se observa uma clara tendência de os gestores 


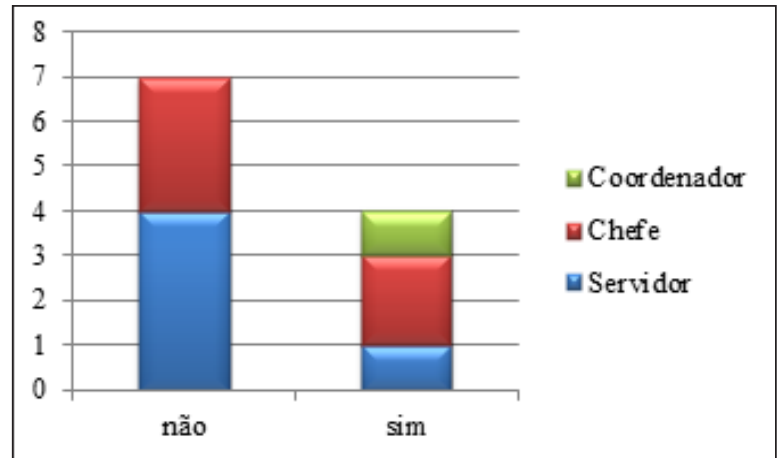

FIGURA 7 - Gráfico sobre a visão dos entrevistados quanto à existência de integração da gestão das UCs partindo do pressuposto de que a gestão integrada depende do planejamento e de tomadas de decisão em conjunto com foco em uma gestão territorial ampla. FONTE: elaboração própria a partir das entrevistas.

vislumbrarem uma maior integração do que os servidores não gestores. No entanto, algumas questões foram respondidas da mesma maneira por todos os entrevistados. São elas:

- Todos os entrevistados veem interligação biológica e física (fluxo gênico, fluxo de espécimes, correntes marítimas, fluxo de sedimentos, etc.) entre as UCs, incluindo o território no qual elas se localizam;

- Todos os entrevistados veem nesse território e nas UCs uma interligação social, seja por meio do uso de recursos do interior e entorno pelos mesmos grupos sociais, seja por outra forma qualquer;

- Todos os entrevistados, tanto os que não acreditam que a gestão integrada já exista quanto os que acreditam, entendem como extremamente importante implementar ou ampliar essa integração, criando ou melhorando uma visão de gestão territorial.

Embora as entrevistas tenham denotado problemas de balizamento de conceitos e de inexistência de real integração entre as UCs, elas mostraram a existência de um solo fértil para que essa cultura de integração germine e floresça. Por exemplo, todos, sem exceção, veem interligação biológica e física entre as UCs, assim como veem nesse território e nas UCs uma interligação social e entendem como extremamente importante implementar ou ampliar a integração entre as UCs, criando ou melhorando uma visão de gestão territorial.

Conforme se observou, de um modo geral os gestores (chefes e coordenador regional) se mostraram mais otimistas com a forma atual da integração entre as UCs. Essa situação pode se explicar pela existência de ações integradas entre os gestores (reuniões, planejamentos, etc.) que talvez não sejam de conhecimento dos servidores. Porém, essa hipótese perde força quando observamos que nem todos os gestores entendem da mesma forma. Por exemplo, quando indagados sobre a existência de integração no planejamento e nas tomadas de decisões das UCs, somente um chefe e o coordenador de uma mesma UC responderam positivamente, o que representa uma não conformidade, já que qualquer integração deveria envolver, no mínimo, duas UCs.

Outra hipótese seria uma diferença de conhecimentos básicos sobre gestão e integração entre gestores e não gestores, estando os gestores defasados nesse quesito. Essa situação é difícil de entender como plausível, sendo que a lógica deveria levar ao contrário.

Talvez a única explicação para tal diferença passe por uma tentativa, por parte dos gestores, de qualificar seus trabalhos como tais, diante de uma situação que claramente mostra-se gerencialmente deficiente.

\subsection{Efetividade do NGI-UMC/SC}

Como de fato existe em vigência uma portaria institucional que estabelece o NGI-UMC/SC, desde 
2011, com diretrizes estabelecidas tanto em sua normativa de criação quanto em um regimento interno, torna-se necessário analisar se estas diretrizes estão sendo cumpridas na prática.

A espinha dorsal do NGI-UMC/SC é a promoção da integração por meio de estruturas colegiadas. Nesse objetivo, ele estabelece um colegiado reduzido, composto pelos responsáveis ou gestores das unidades descentralizadas, com função de coordenar os trabalhos, e um colegiado ampliado, composto pela totalidade dos servidores das unidades descentralizadas, com a função de planejar e avaliar as ações do NGI-UMC/SC.

Esses colegiados funcionariam por meio de reuniões periódicas, nas quais o colegiado ampliado deveria se reunir no início e ao final de cada ano, para planejamento e avaliação das ações, podendo reunir-se, também, sempre que convocado. Já o colegiado reduzido deveria se reunir todo mês ou, ainda, sempre que convocado. Em ambos os casos, suas discussões e deliberações deveriam ser postas em ata, redigida por um dos participantes, e encaminhadas à secretaria do NGI-UMC/SC, para comunicação e arquivo.

Porém, conforme a análise das atas, a última reunião do colegiado reduzido, que deveria se reunir mensalmente, se deu em 24/09/2014, portanto, há quase dois anos. Já o colegiado ampliado, que deveria reunir-se semestralmente, não se reúne desde 05/12/2013, ou seja, há dois anos e meio.

O NGI-UMC/SC deveria também elaborar anualmente Planos Operativos que contemplariam suas ações e atividades integradas, além de orientar a destinação de recursos orçamentários e extraorçamentários para o conjunto de unidades que o compõe. Como não poderia deixar de ser, tendo em vista o grande hiato desde as últimas reuniões colegiadas, não existe nenhum plano hoje vigente.
A fim de auxiliar no detalhamento e no planejamento das ações integradas, deveriam ser instituídos câmaras técnicas, grupos de trabalho ou outros instrumentos com esses objetivos. Nesse caso, também esses instrumentos atualmente são inexistentes ou encontram-se inoperantes.

Como para o cumprimento das ações definidas pelo NGI-UMC/SC, além da união de esforços, o coletivo também deveria definir no seu planejamento o melhor uso dos recursos humanos, materiais e financeiros destinados às unidades, analisou-se também esse parâmetro como indicador de sua efetividade, com foco nos recursos de compensação ambiental. Como a maioria dos entrevistados já havia declarado que esses recursos não eram geridos coletivamente, buscou-se, objetivando corroborar melhor essa questão, um exemplo que fosse representativo. Foi analisada então a execução dos recursos provenientes da compensação do campo de produção de óleo e gás de Bijupirá \& Salema, que não só foi a compensação ambiental de valor mais significativo que já beneficiou as unidades em análise, mas foi destinada desde o início por meio do programa RUMAR, objetivando a integração dessas unidades. Porém, a empresa judicializou a questão, sendo que o pagamento da compensação ambiental ocorreu somente em 2013, quando a Base REBIO Arvoredo recebeu R \$ 4.630.139,86, valor este que se encontra em fase de execução, conforme consta no referente processo administrativo. Nesse caso, observou-se que todo recurso vem sendo gerido exclusivamente pela REBIO Arvoredo e que, além de aplicações isoladas, como a compra de alguns computadores e de um veículo a serem destinados a outras unidades, esse montante tem beneficiado somente as demandas da Reserva Biológica.

Se por um lado o NGI-UMC/SC encontra-se inoperante, contrariando uma portaria institucional vigente, por outro se observou, pelas atas e demais 
documentos existentes, que entre 2011 e 2014 ocorreram diversas reuniões colegiadas, inclusive com a formação de câmaras técnicas e grupos de trabalho. Aparentemente, conforme relatado por alguns entrevistados, o que faltaria para a retomada dos trabalhos do NGI-UMC/SC seria uma maior postura e cobrança institucional e a existência de alguns servidores que pudessem se dedicar ao processo, principalmente atuando na secretaria do NGI. Ou seja, aparentemente os elementos para se retornar ao caminho da integração encontram-se disponíveis.

\subsection{Reflexões sobre a integração da gestão das UCs Marinho-Costeiras}

Embora tenham sido observados trabalhos envolvendo o apoio entre as UCs, estes não podem ser caracterizados como parte de uma gestão integrada, já que a mesma deveria partir da premissa de que, além das ações, o planejamento e as decisões sejam construídos de forma conjunta, visando ao território como um todo.

Na ausência da visão de gestão territorial integrada, os focos de gestão das UCs também acabam por possuir cruciais diferenças que não se justificam somente pela heterogeneidade de suas categorias, e essas disparidades acabam por extrapolar para a forma como a instituição se relaciona com a sociedade do entorno. Tal situação representa maior gravidade nas áreas onde esses entornos se sobrepõem.

Importante salientar que a gestão das UCs de forma isolada, além de representar um desperdício de recursos humanos e financeiros investidos nos esforços de integração e uma gestão desarticulada do território, também se caracteriza como um descumprimento frontal às previsões legais e às normas institucionais, representadas pelo regramento cons- tante no SNUC e em seu decreto regulamentador, assim como na portaria de criação do NGI-UMC/ $\mathrm{SC}$ e em seu regimento interno.

Observa-se também uma diferença de compreensão dos conceitos e objetivos da integração entre servidores, o que denota uma necessidade de capacitação e balizamento de conceitos. Para muitos se observa que a integração é fortemente entendida como um simples conjunto de atividades de ajuda mútua, objetivando somente suprir as deficiências de recursos humanos e financeiros, sendo que, em um contexto ideal de equipes e recursos orçamentários, a integração não seria necessária.

Outro grande problema identificado ao longo do trabalho foi o afastamento da sociedade da discussão sobre a gestão territorial dessa região, sendo essa participação hoje feita de forma fragmentada pelas UCs, que a promove isoladamente. Contudo, vale ressaltar que a gestão integrada proposta pelo NGI-SC não prevê a gestão participativa de suas UCs.

Ao se analisar as motivações que dificultam a integração entre as UCs federais marinho-costeiras de Santa Catarina, observa-se que a grande razão que talvez esteja por trás disso seja a forma como a instituição cobra resultados dessas unidades. Essas cobranças estão muito atreladas a ações e à constituição de ferramentas de gestão institucionalmente definidas, como elaboração de planos de manejo, constituição de conselhos gestores, respostas a procedimentos no prazo, entre outras, mas não com resultados da missão da instituição, como a manutenção da biodiversidade ou do modo de vida das populações tradicionais. Ou seja, os gestores e servidores cumprem seu papel realizando as ações tradicionalmente definidas pela instituição, independentemente se essas estão efetivamente garantindo a conservação do território ou não. 
Se o objetivo dos servidores fosse a real conservação do território, mensurada por meio de monitoramento sistemático, certamente se sentiriam obrigados a buscar uma integração para atingi-lo, pois do contrário a tarefa seria muito difícil. Certamente as pessoas se integram mais facilmente quando possuem um objetivo comum, mas no caso, mesmo com a existência de toda a legislação nesse sentido, isoladamente os gestores e servidores são demandados por objetivos individuais.

\section{Conclusão}

É necessária uma real integração das UCs federais em análise, a qual não deverá se limitar a suprimir as deficiências estruturais do órgão público, mas também garantir o atendimento às exigências legais, às normativas institucionais e às decisões coletivas, alcançando uma maior coerência da gestão territorial, assim como uma maior eficiência na conservação dos ecossistemas e na manutenção e no ordenamento dos serviços a eles associados.

Tal resultado somente se consolidará com a transformação dos dispositivos legais e normativos, assim como dos programas construídos coletivamente em diretrizes institucionais con-

\section{Referências}

Asmus, M. L.; Kitzmann, D. I. S.; Laydner, C. Gestão costeira no Brasil: estado atual e perspectivas. Montevideo: Ecoplata, 2004. 63 p.

Boni, V.; Quaresma, S. V. Aprendendo a entrevistar: como fazer entrevistas em Ciências Sociais. Em Tese, 2(1), 6880, 2005.

Brasil. Lei $n^{\circ}$. 6.938, de 31 de agosto de 1981. Dispõe sobre a Política Nacional do Meio Ambiente, seus fins e mecanismos de formulação e aplicação, e dá outras providências. Brasília: DOU de 09.09.1981. solidadas. Lembrando sempre da necessidade do envolvimento da sociedade nos fóruns legalmente estabelecidos e nos meios informais que também podem facilitar esse envolvimento. Para se alcançar esse objetivo, as diretrizes deverão ser seguidas independentemente do perfil, inclinação ou mesmo vontade pessoal dos gestores públicos, que deverão ser fiscalizados e cobrados pela sociedade, assim como pelas instâncias hierárquicas superiores da instituição.

Toda essa questão seria mais bem tratada com a institucionalização de um mosaico nos moldes previstos no SNUC, no qual o Conselho do Mosaico traria a participação da sociedade à gestão do território como um todo.

Por fim, no caso das UCs em análise, observa-se grande potencial institucional e vontade, dos servidores e gestores, em se atingir a integração e a visão territorial na gestão. Também se observa a existência de recursos, em especial de compensações ambientais, capazes de dar estrutura para que essa gestão se efetive. Dessa forma, o que aparentemente faz falta é tão somente um posicionamento institucional condizente com as diretrizes existentes, os princípios da conservação da biodiversidade e os interesses da coletividade.

Brasil. Decreto $n^{\circ}$. 94.656, de 20 de julho de 1987. Cria as Estações Ecológicas de Carijós, Pirapitinga e Tupinambás, e dá outras providências. Brasília: DOU de 21.07.1987.

Brasil. Lei $n^{\circ}$. 7.661, de 16 de maio de 1988. Institui o Plano Nacional de Gerenciamento Costeiro e dá outras providências. Brasília: DOU de 18.05.1988.

Brasil. Decreto $n^{\circ}$. 99.142, de 12 de março de 1990. Cria a Reserva Biológica Marinha do Arvoredo. Brasília: DOU de 12.03.1990. 
Brasil. Decreto Federal $n^{\circ} 528$ de 20 de maio de 1992. Cria a Área de Proteção Ambiental do Anhatomirim. Brasil, 1992a. Brasília: DOU de 20.05.1992.

Brasil. Decreto $n^{\circ}$. 533, de 20 de maio de 1992. Cria a Reserva Extrativista do Pirajubaé, e dá outras providências. Brasil, 1992b. Brasília: DOU de 21.05.1992.

Brasil. Resolução CIRMn ${ }^{\circ}$ 05, de 03 de dezembro de 1997. Aprova o Plano Nacional de Gerenciamento Costeiro II (PNGC II). Disponível em: <www.mma.gov.br/component/phocadowload/category/33-gerenciamento-costeiro>. Acesso em: 20 abr. 2016.

Brasil. Lei $n^{\circ}$. 9.605, de 12 de fevereiro de 1998. Dispõe sobre as sanções penais e administrativas derivadas de condutas e atividades lesivas ao meio ambiente, e dá outras providências. Brasília: DOU de 13.02.1998.

Brasil. Lei no . 9.985, de 18 de julho de 2000a. Regulamenta o art. 225, $\S 1^{\circ}$, incisos I, II, III e VII, da Constituição Federal, institui o Sistema Nacional de Unidades de Conservação da Natureza e dá outras providências. Brasília: DOU de 19.07.2000.

Brasil. Decreto Federal s/n, de 14 de setembro de $2000 b$. Cria a Área de Proteção Ambiental da Baleia Franca. Brasília: DOU de 14.09.2000.

Brasil. Decreto $n^{\circ}$. 5.300, de 7 de dezembro de 2004. Regulamenta a Lei $\mathrm{n}^{\circ} 7.661$, de 16 de maio de 1988, que institui o Plano Nacional de Gerenciamento Costeiro - PNGC, dispõe sobre regras de uso e ocupação da zona costeira e estabelece critérios de gestão da orla marítima, e dá outras providências. Brasília: DOU de 8.12.2004.

Brasil. Decreto Federal no. 5.758, de 13 de abril de 2006. Institui o Plano Estratégico Nacional de áreas protegidas PNAP, seus princípios, diretrizes, objetivos e estratégias, e dá outras providências. Brasília: DOU de 17.04.2006.

Cifuentes M. A.; Izurieta A. V.; Faria, H. H. Medición de la Efectividad del Manejo de Areas Protegidas. Turrialba: WWF/IUCN/GTZ, 2000.

Debetir, E. Gestão de unidades de conservação sob influência de áreas urbanas: diagnóstico e estratégias de gestão na Ilha de Santa Catarina-Brasil. Florianópolis, SC, 2006. 247 p. Tese (Doutorado em Engenharia Civil) - Programa de Pós-Graduação em Engenharia Civil. Universidade Federal de Santa Catarina.
IBAMA - Instituto Brasileiro do Meio Ambiente e dos Recursos Naturais Renováveis. Plano de manejo da Estação Ecológica de Carijós. IBAMA, 2003. Disponível em: $<\mathrm{http}$ ://www.icmbio.gov.br/portal/unidadesdeconservacao/ biomas-brasileiros/marinho/unidades-de-conservacao-marinho/2251-esec-de-carijos>. Acesso em: maio 2016.

IBAMA - Instituto Brasileiro do Meio Ambiente e dos Recursos Naturais Renováveis. Plano de Manejo da Reserva Biológica Marinha do Arvoredo. IBAMA, 2004. Disponível em: <http://www.icmbio.gov.br/portal/unidadesdeconservacao/biomas-brasileiros/marinho/unidades-de-conservacao-marinho//2276-rebio-marinha-do-arvoredo $>$. Acesso em: 20 maio 2016.

IBAMA - Instituto Brasileiro do Meio Ambiente e dos Recursos Naturais Renováveis. Processo IBAMA $n^{\circ}$ 02070.002416/2008-20. IBAMA, 2008 - Assunto: O Programa Rede de Unidades Costeiras e Marinhas do IBAMA - RUMAR. Disponível para análise física do processo na sede da Coordenação Geral de Pesquisa e Monitoramento da Biodiversidade - CGPEQ da diretoria de pesquisa, avaliação e monitoramento da biodiversidade - DIBIO, na Sede do ICMBio em Brasília/DF. Acesso em: 19 maio 2016.

ICMBIO - Instituto Chico Mendes de Conservação da Biodiversidade. Portaria $n^{\circ} 32$, de 20 de maio de 2011. Cria o Núcleo de Gestão Integrada de Unidades Marinho-Costeiras de Santa Catarina - NGI-UMC/SC. Brasília/DF: ICMBio, 2011a. Disponível em: $<$ http://pesquisa.in.gov.br/imprensa/ jsp/visualiza/index.jsp?data $=23 / 05 / 2011 \&$ jornal $=1 \&$ pagin $\mathrm{a}=78 \&$ totalArquivos=160>. Acesso em: maio 2016 .

ICMBIO - Instituto Chico Mendes de Conservação da Biodiversidade. Monitoria do Plano de Manejo ESEC Carijós. Brasília/DF: ICMBio, 2011b. Disponível em: $<$ http://www.icmbio.gov.br/portal/unidadesdeconservacao/ biomas-brasileiros/marinho/unidades-de-conservacao-marinho/2251-esec-de-carijos>. Acesso em: 19 maio 2016.

ICMBIO - Instituto Chico Mendes de Conservação da Biodiversidade. Portaria $n^{\circ}$ 95, de 5 de setembro de 2012. Aprova o Regulamento Interno da Fiscalização do Instituto Chico Mendes de Conservação da Biodiversidade - ICMBio, que estabelece os procedimentos para atuação da fiscalização no âmbito deste Instituto. Brasília: DOU de 11 de setembro 2012.

ICMBIO - Instituto Chico Mendes de Conservação da Biodiversidade. Plano de Manejo da Área de Proteção 
Ambiental do Anhatomirim. Brasília/DF: ICMBio, 2013. Disponível em: <http://www.icmbio.gov.br/portal/unidadesdeconservacao/biomas-brasileiros/marinho/unidades-de-conservacao-marinho/2239-apa-de-anhatomirim>. Acesso em: 20 maio 2016.

ICMBIO - Instituto Chico Mendes de Conservação da Biodiversidade. Dados vetoriais com tabela de atributos das autuações administrativas lavradas pelo ICMBio. Informações disponíveis ao acesso público na Coordenação Regional do ICMBio em Florianópolis. ICMBio, 2016a. Acesso em: 26 abr. 2016.

ICMBIO - Instituto Chico Mendes de Conservação da Biodiversidade. Dados Vetoriais Limites das Unidades de Conservação Federais. ICMBio, 2016b. Disponível em: $<$ http://www.icmbio.gov.br/portal/unidadesdeconservacao/ biomas-brasileiros/marinho/unidades-de-conservacao-marinho>. Acesso em: 20 maio 2016.

MMA - Ministério do Meio Ambiente. Portaria $n^{\circ} 17$, de 14 de janeiro de 2002. Institui Grupo de Trabalho-GT para promover estudos que viabilizem a forma de gestão integrada do conjunto das Unidades de Conservação marinho-costeiras do Estado de Santa Catarina. Brasília: DOU de 15 de janeiro 2002.

MMA - Ministério do Meio Ambiente. Projeto TerraMar, 2015. Disponível em:<www.mma.gov.br/gestao-territorial/ projeto-terramar>. Acesso em: 28 abr. 2016.

Sales, G. Desafios e perspectivas para gestores de unidades de conservação. In: Cases, M. O. (Org.). Gestão de unidades de conservação: compartilhando uma experiência de capacitação. Brasília: WWF-Brasil e IPÊ, 2012. p. 307-330.

Scherer, M. E.G.; Asmus, M. L. Ecosystem - Based Knowledge and Management as a tool for Integrated Coastal and Ocean Management: A Brazilian Initiative. Journal of Coastal Research, 75(10), 2016.

Souza, M. J. L. O território: sobre espaço e poder, autonomia e desenvolvimento. Geografia: conceitos e temas. Rio de Janeiro: Bertrand Brasil, 1995. p. 77-116. 